\title{
Sistem Autentikasi Hotspot Menggunakan LDAP dan Radius pada Jaringan Internet Wireless Prodi Teknik Sistem Komputer
}

\author{
Ahmad Herdinal Muttaqin ${ }^{1)}$, Adian Fatur Rochim ${ }^{2)}$, Eko Didik Widianto ${ }^{2)}$ \\ Program Studi Sistem Komputer, Fakultas Teknik, Universitas Diponegoro \\ Jalan Prof. Sudharto, Tembalang, Semarang, Indonesia
}

\begin{abstract}
Wireless network is a network utilizing radio waves that propagate openly. This network requires security to simplify the process by using user Authentication. One of technology that could be used in order to make it safer is a Lightweight Directory Access Protocol (LDAP) and Remote Authentication Dila In User Service (RADIUS). Computer Systems Engineering Department is one of the study program in the Faculty of Engineering, University of Diponegoro that reserve the internet service everyday for students need. However, internet wireless network in this department is not yet safe enough,for the necessary to secure it's need creating a security system with LDAP and RADIUS.The results of this study is a network authentication server using OpenLDAP and FreeRadius Hotspot that will be integrated with an account of Academic Information System, which is implemented on Prodi Computer Systems Engineering Department of the University of Diponegoro.
\end{abstract}

Keywords : OpenLDAP, FreeRadius, Wireless, Hotspot, Lightweight Directory Access Protocol (LDAP), Remote Authentication Dial In User Service (RADIUS).

\section{PENDAHULUAN}

$\mathrm{S}$ aat ini beragam cara yang dapat dilakukan untuk memanfaatkan layanan internet mulai dari cara yang konvensional sampai pada pemanfaatan teknologi komunikasi bergerak. Prodi Teknik Sistem Komputer adalah salah satu prodi di Fakultas Teknik Universitas Diponegoro yang mempunyai layanan internet wireless untuk kebutuhan mahasiswa sehari-hari dalam mencari data dan informasi Akan tetapi jaringan wireless internet dijurusan ini belum cukup aman.

Berawal dari masalah-masalah tersebut banyak metode pengamanan jaringan wireless dari sekala pengamnan sederhana seperti seperti wpa (wifi Protected Access), wpa2, wpa-psk dan sekala besar seperti metode sejenis yaitu sistem keamanan wireless perhotelan, perkantoran, dan perumahan yang menggunanakn captive portal. Selain ituada juga contoh fasilitas hotspot cakupan area seperti produk wifiid yang diluncurkan oleh ISP (Internet Service Provider)Telkomsel untuk bisa menggunakan aksesinternet di berbagai cakupan daerah di Indonesia, informasi ini dikutip di www.wifiid.com yang menjelaskan pengguna diharuskan membeli voucher untuk bisa mendapatkan akses internet di area yang sudah mencakup sinyal wifiid.
Berbagai macam bentuk pengamanan jaringan wireless sudah ada dan banyak ditemui di sekitar kita akan teteapi bentuk pengamanan jaringan wirless ini harus disesuaikan dengan situasi dan kondisi lingkungan yang ada. Seperti halnya pada dilingkungan kampus universitas diponegoro dengan memaanfatkan akun SIA (Sistem Informasi Akademik) yang bisa di integrasikan dengan pengamanan jaringan hotspot menggunakan LDAP dan RADIUS.Manfaat yang didapat dalam sistem ini adalah kemudahan bagi setiap mahasiswa Sistem Komputer yang hanya mempunyai satu akun terintegrasi untuk bisa mendapatkan fasilitas internet tanpa mengenyampingkan aspek keamanan yang ada.

\section{METODOLOGI PENELITIAN}

Metodologi penelitian yang digunakan pada sistem autentikasi jaringan hotspot menggunakan Lightweight Directory Access Protocol (LDAP) dan remote authentication dial in user service (RADIUS) pada jaringan internet wireless prodi Teknik Sistem Komputer digambarkan pada Gambar 1 di bawah ini.

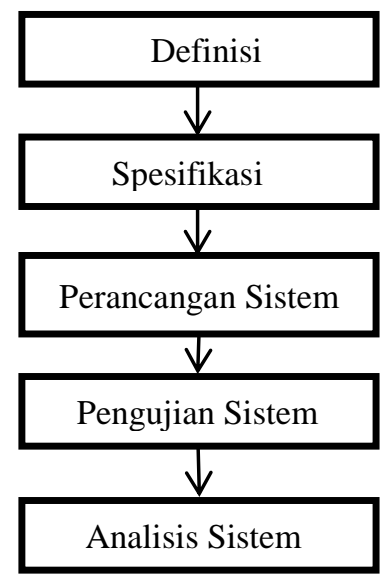

Gambar 1 Metode penelitian

Model ini melingkupi aktifitas-aktifitas sebagai berikut,

1. Definisi Sistem

Mendefinisikan sistem yang akan dibuat dengan penjabaran awal sistem, identifikasi kebutuhan sistem, tujuan dan manfaat sistem, cara kerja sistem dan topologi jaringan sistem.

2. Spesifikasi Kebutuhan

Proses spesifikasi kebutuhan akan menjabarkan tentang awal perancangan sistem dengan menentukan spesifikasi 
kebutuhan yang sesuai definisi sistem. Spesifikasi kebutuhan terdiri atas spesifikasi perangkat keras dan perangkat lunak. Kegiatan ini menentukan arsitektur sistem secara keseluruhan. Perancangan perangkat lunak melibatkan identifikasi dan deskripsi abstraksi sistem perangkat lunak yang mendasar dan hubungan-hubungannya.

3. Konfigurasi Sistem

Pada tahap ini, spesifiikasi kebutuhan yang telah di tentukan akan di rancang sesuai topologi/desain jaringan dan direalisasikan sebagai serangkaian program atau unit program yang memungkinkan untuk menjalankan tujuan sistem pada cara kerja sistem.

\section{Pengujian Sistem}

Unit program diintegrasikan dan diuji sebagai sistem yang lengkap untuk menjamin bahwa persyaratan sistem telah dipenuhi. Setelah pengujian sistem, sistem siap digunakan dan dianalisis.

5. Analisis Sistem

Unit yang telah diuji akan dilakukan analisis untuk mendapatkan hasil yang diinginkan.

\section{PERANCANGAN SISTEM}

Definisi sistem akan menjabarkan awal sistem dibuat, tujuan, manfaat sistem, topologi jaringan dan cara kerja sistem yang akan digunakan untuk menentukan spesifikasi kebutuhan sistem ke tahapa selanjutnya, beberapa tahapan untuk bisa mendeffinisikan sistem yang telah dibuat adalah sebagai berikut:

\section{A. Inisialisasi awal sistem}

Pada tahap ini sistem dibuat sesuai dengan kebutuhan layanan jaringan wireless yang ada di kampus Teknik Sistem Komputer dengan pemanfaatan fasilitas komputer yang bisa digunakan untuk kebutuhan peniliatan. Sistem yang digunakandidalam penelitian ini menggunakan LDAP dan RADIUS yang saling terintegrasi dalam pencocokan akun dilengkapi dengan captive portal sebagai antarmuka dalam proses login jaringan hotspot.

\section{Topologi Jaringan}

Sistem ini didesain terlebih dahulu menggunakan topologi jaringan. Topologi jaringan merupakan hal yang menjelaskan hubungan geometris antara unsur-unsur dasar penyusun jaringan, yaitu node, link, dan station. Topologi jaringan sistem ini dibuat dengan aplikasi Microsoft visio yang disusun sesuai kebutuhan sistem yang akan dibuat. Berikut topologinya

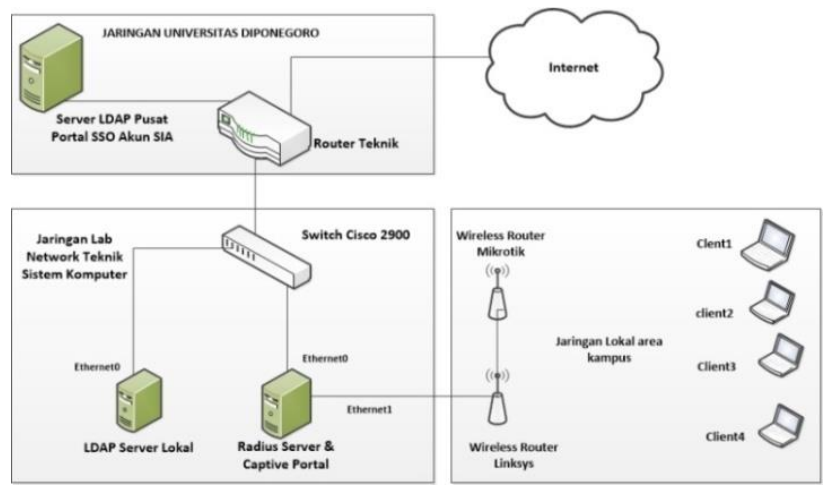

Gambar 2 Topologi Jaringan

\section{Cara Kerja Sistem}

Sistem autentikasi jaringan hotspot menggunakan LDAP dan RADIUS terdiri atas 2 server yang tersedia. Dimana LDAP server akan menjadi server directory database sedangkan server RADIUS adalah server autentikasi dan captive portal sebgai antarmuka langsung ke jaringa lokal hotspot kampus. tersebut akan diakses oleh klien melalui jaringan lokal. Cara kerja sistem autentikasi hotspotmenggunakan LDAP dan RADIUS ini akan dijelaskan pada Gambar 3.

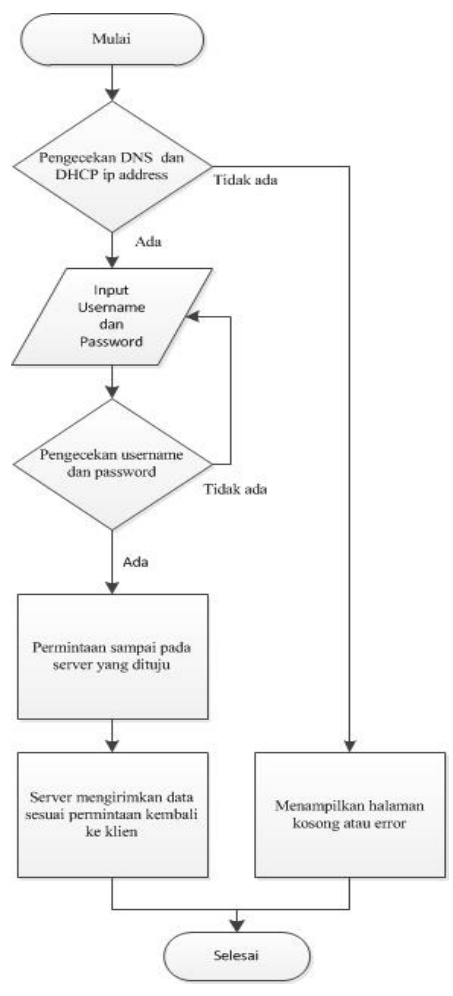

Gambar 3 Diagram alir cara kerja sistem

B. Spesifikasi Kebutuhan

\section{Spesifikasi Perangkat Keras}

Didalam penilitian ini digunakan 2 komputer server yang berada di laboratorium jaringan berikut spesifikasinya:

1. Server 1

Server ini digunanakan sebagai server LDAP untuk penyimpanan database accaount user

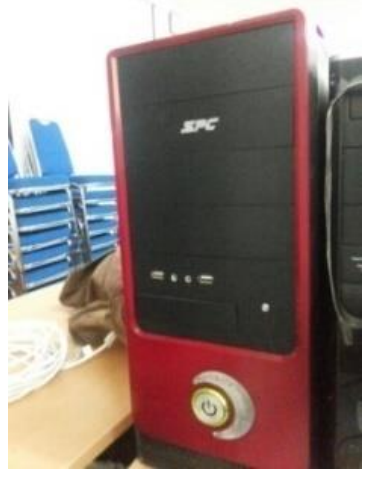

Gambar 4.Spesifikasi server 1. 
Perangkat keras yang digunakan dalam penelitian tugas akhir ini adalah seperti yang terlihat pada Gambar 3 mempunyai sepesifikasi ProcessorIntel Cori3 Processor, 2.8GHz; RAM $4 \mathrm{Ghz}$ RAM; SystemManufactureMSI, Lan PCI Xpress dan penyimpanan memory Hardisk sebesar 250 Ghz

2. Server 2

Server ini digunakan sebagai server RADIUS yang berfungsi melakukan autentikasi data informasi account pada server LDAP.

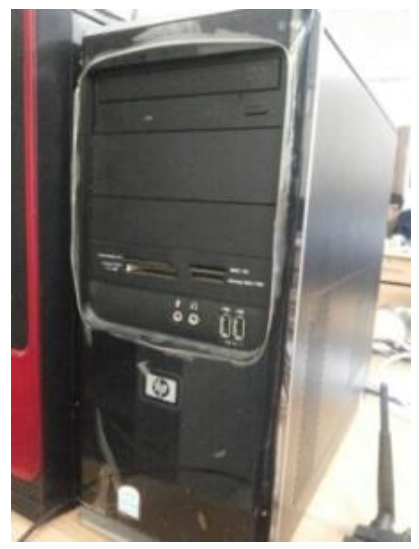

Gambar 5 Spesifikasi server 2

Perangkat keras yang digunakan dalam server ini meliputi ProcessorIntel Core 2 duo, RAM 1Ghz 2 LAN PCI Xpress media penyimpanan Hardisk $150 \mathrm{Ghz}$ dan System Manufacture HP (Hewlett Packard) .

\section{Router Linksys WRT54GL}

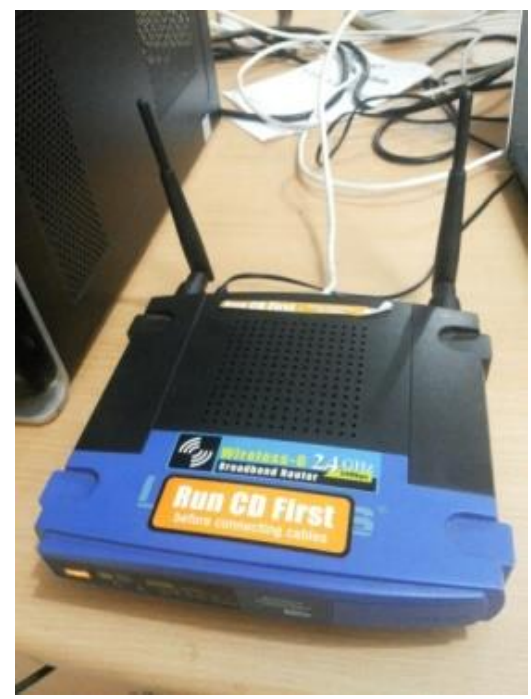

Gambar 6 Router Linksys

Spesifikasi dari router Linksys adalah sebagai berikut All in one internet sharing router, 4 port switch dan 54 Mbps wireless-G $802.11 \mathrm{~g}$ access point. Shares a single internet connection and other resoureces dengan kabel Ethernet dan Wireless-G High security :TKIP dan AES encryption, wireless Mac addrees filtering, powerful SPI firewall.
2. Spesifikasi Perangkat Lunak

1. Sistem Operasi Ubuntu Server 14.04

Pada komputer yang akan menjalankan LDAP server telah tertanam sistem operasi Ubuntu berbasisi LINUX 64 bit. Ubuntu merupakan salah satu distribusi Linux yang berbasiskan Debian dan didistribusikan sebagai perangkat lunak bebas.Ubuntu versi ini dirancang untuk kepentingan penggunaan server. Sistem operasi ini digunakan pada LDAP server dan RADIUS server

2. OpenLDAP

Perangkat lunak yang bersifat opensource untuk menjalankan server ldap sebgai pengelola directori database. Perangkat lunak ini release terbaru dengan versi openldap 2.4.4.

3. PHPLDAPAdmin

Selain OpenLDAP didalam server LDAP juga terdapat PHPLDAPAdmin sebagai antarmuka pengelolaan database khusus LDAP berbasis web dengan versi 1.2.

4. FreeRADIUS

FreeRADIUS adalah perangkat lunak yang bersifat opensource untuk menjalankan server RADIUS versi yang digunakan yaiut FreeRADIUS 2.2.7.

5. CoovaChilli

CoovaChilli merupakan perangkat lunak captive portal geratis pegembangan dari chillispot.Pada system ini digunakan covachilli versi 1.3.0.

6. PHP 5

PHP adalah bahasa pemrograman dengan semua sintaks yang diberikan akan sepenuhnya dijalankan pada server dan hasilnya dikirimkan ke browser. Versi PHP yang digunakan dalam tugas akhir ini adalah PHP versi 5.

7. LAMPP

LAMPP adalah sebuah aplikasi web serverApache yang di dalamnya sudah tersedia database server MySQL dan support php programming. Komponen LAMPP yaitu Apache, PHP, MySQL dan phpMyAdmin.LAMPP merupakan aplikasi yang mudah digunakan, gratis dan mendukung instalasi di Linux dan Windows.Keuntungan lainnya adalah cuma menginstal satu kali sudah tersedia Apache Web Server, MySQL DatabaseServer, PHP Support (PHP 4 dan PHP 5) dan beberapa modul lainnya.

8. BIND

BIND merupakan salah satu implementasi DNS yang paling banyak digunakan pada server di Internet. BIND yang digunakan pada virtualisasi jaringan ini adalah BIND9 yang berjalan pada sistem operasi UbuntuServer 14.04 .

9. Putty

Putty adalah aplikasi terminal akses yang digunakan untuk buat remoteconnection komputer melalui port SSH atau sebagainya. 


\section{Pengujian Unit}

Berdasarkan perancangan sistem yang telah dibuat pada BAB 3, maka dihasilkan sebuah sistem autentikasi hotspot menggunakan LDAP dan RADIUS.Sistem ini menyediakan infrastruktur keamanan yang berdasarikan autentikasi data informasi akun pada direktori terpusat bertujuan untuk efisiensi pengelolaan jaringan lokal dalam penggunan jaringan internet kampus. Pemanfaatan teknologi ini mengharuskan klien melakukan proses autentikasi terlebih dahulu sebelum menggunakan fasilitas internet, jika tidak maka penggunaan akses internet tidak bisa digunakan. Tahap pengujian pertama dalam sistem ini adalah melakukan pengujian terhadap sistem autentikasi hotspot menggunakan LDAP dan RADIUS. Tahapan ini terbagi menjadi dua skenario pengujian yang dilakukan oleh admin, antara lain sebagai berikut:

1. Skenario pengujian server LDAP dan antarmuka Phpldapadmin

2. Skenario pengujian server RADIUS dan Captive portal

\section{PengujianServerLDAP}

Tahap pengujian ini dilakukan untuk mengetahui bagaimana cara menggunakan dan mengelola sebuah Server LDAP menggunakan OpenLDAP yang berfungsi sebaga backend database yang digunakan untuk penyimpanan akun login user, selain itu ditambahkan juga antarmuka phpldapadmin yaitu perangkat lunak yang berbasis web yang berfungsi untuk mengatur dan memudahkan pengelolaan akun di dalam LDAP server melalu web browser. Untuk memulai pengujian server ini kita jalankan server yangs sudah terinstal Ubuntu Server 14.04 dan Openldap. Berikut adalah komputer server yang sudah terinstall Ubuntu Server 14.04dan Openldap yang ditunjukan pada Gambar 7

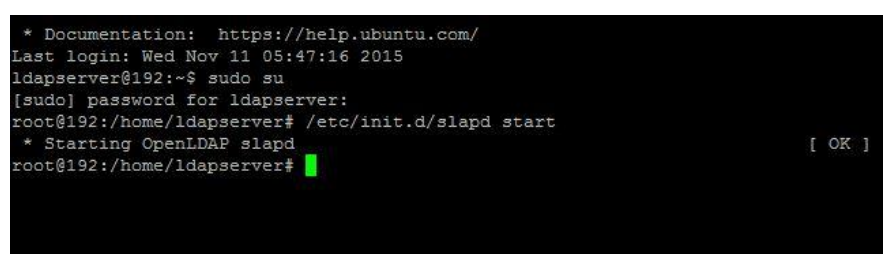

Gambar 7 Pengujian integrasi login sistem

Setelah Openldap dijalankan pengelolaan databases bisa diakses langsung melalui perangkat lunak berbasis web yaitu phpldapadmin yang bisa diakses melalui web browser dengan mengetikan alamat url ip address seperti berikut 10.42.12.55/phpldapadmin seperti ditunjukan pada Gambar 8

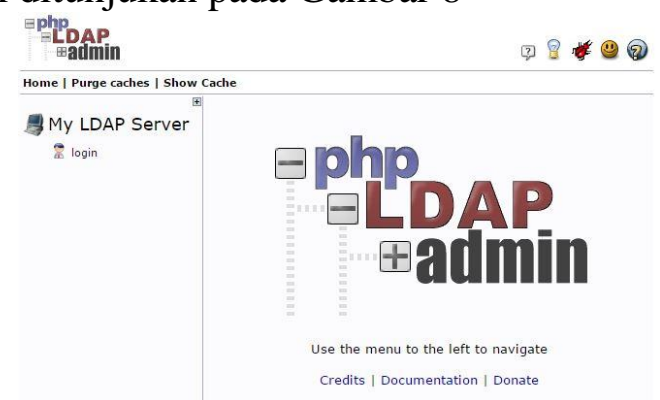

Gambar 8 Tampilan Phpldapadmin

\section{Prngujian Server RADIUS}

Pengujian server RADIUS dilakukan dengan cara menguji hasil konfigurasi dan sinkronisasi terhadap server LDAP untuk proses autentikasi user ketika login. Porses ini memungkinkan server RADIUS meneruskan paket data akun user yang diminta user dan melakukan sinkronisasi antara server LDAP apakah data user yang di request teruatentikasi atau tidak.Dalam pengujian ini server RADIUS menggunakan perangkat lunak Freeradius yang bersifat opensource yang bisa digunakan sebagai radius server.Untuk memulai pengujian telah disiapkan sebuah komputer server yang sudah terinstal Ubuntu server 14.04 dan freeradius server. Dalam server ini freeradius telah selesai dikonfigurasi pada file modul ldap untuk bisa binding ke server ldap seperti pada Gambar 9

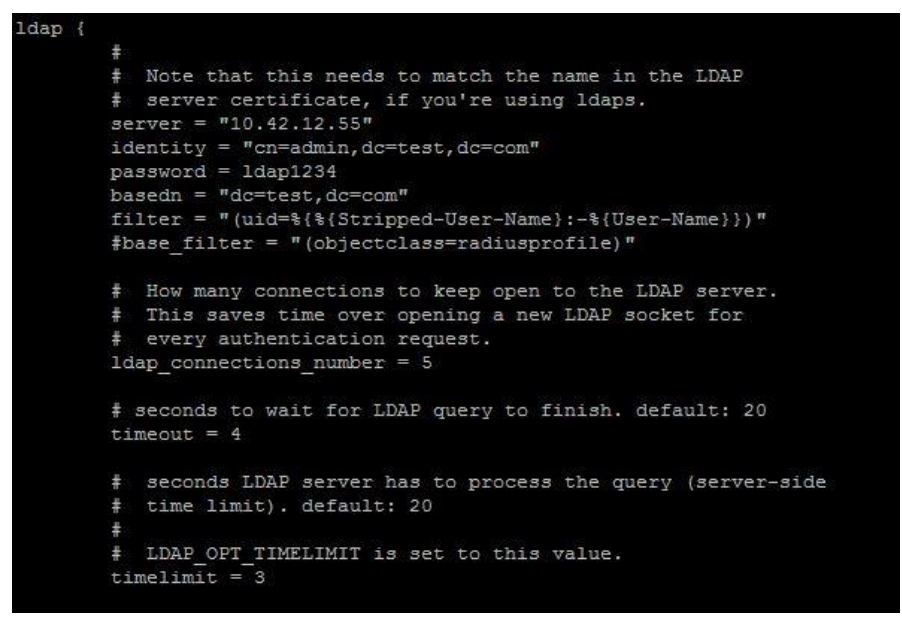

Gambar 9 File Modul Ldap

File modul ldap ini yang berfungsi untuk singkronisasi dengan server ldap agar bisa saling terhubung ketika proses autentikasi berjalan. Dalam file modul LDAP ini kita diminta mengisi sertifikat server agar server RADIUS bisa mengakses server LDAP untuk mengambil data dari database dengan mengisi perintah "server = "10.42.12.55"" yaitu IP address server LDAP, domain component beserta password administrator server LDAP "identity = "cn=admin, dc=test, dc=com"', password = ldap1234. Selanjutnya setelah semua proses konfigurasi selesai kita menjalankan debug program freeradius agar bisa mengeksekusi file yang telah dimodifikasi. Terlebih dahulu kita harus mengheentikan dengan perintah /etc/init.d/freeradius stop, setelah itu jalankan perintah freeradius $-\mathrm{X}$ seperti yang ditunukan pada Gambar 10 .

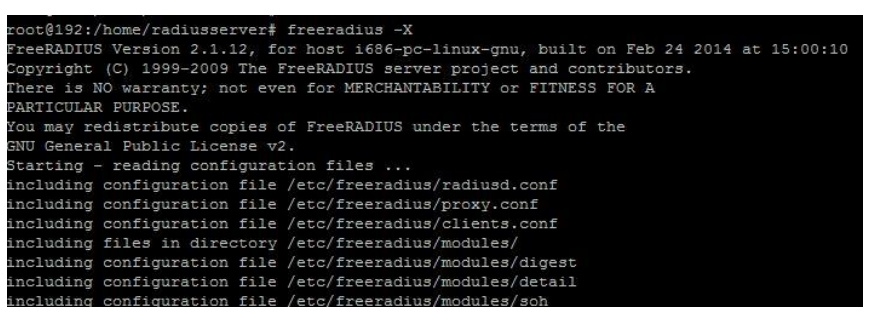

Gambar 10 Run Freeradius -X 
Setelah menjalankan freeradius langkah selanjutnya adalah mencoba melakukan radtest ke server ldap. Radtest adalah perintah yang dilakukan untuk mencoba mengambil data user oleh server radius untuk membuktikan proses binding ke server ldap telah tersambung. Kita akan mencoba melakukan radtest ke akun user yang telah teredaftar di server ldap yaitu akun Asep Unyil. Perintah radtest bisa kita lihat pada Gambar 11

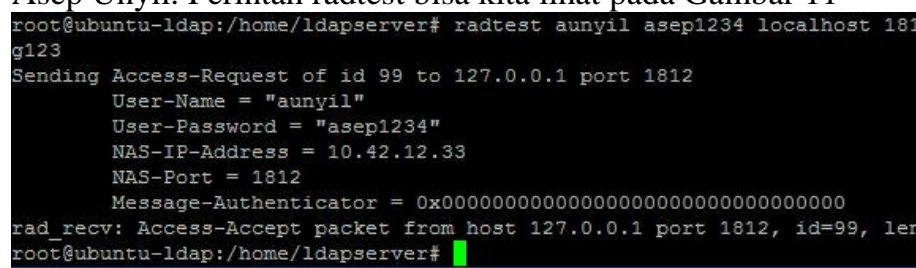

Gambar 11 Testing Radtest

\section{Pengujian Captive Portal}

Pengujian captive portal ini dilakukan bersamaan dengan penjugian RADIUS dikarenakan komputer server yang dipakai untuk keduanya sama dalam satu server. Pengujian captive portal ini dilakukan dengan menguji proses autentikasi, tampilan antarmuka dan sistem yang dibangun agar semua interkoneksi jaringan dari local ke public berhasil diblok oleh captive portal. Selain itu pengujian ini mengharuskan caprive portal bisa terhubung ke server RADIUS dalam mengambil data user di server LDAP.Dalam pengujian ini pernagkat lunak yang dipakai untuk membuat captive portal adalah coovachilli yang sudah terinstall pada computer server yang memiliki sistem operasi Ubuntu Server 14.04 dan syaratnya komputer server ini harus memiliki 2 ethernet card.Ethernet 1 terhubung ke jaringan internet dan Ethernet 2 terhubung ke jaringan local.tahapan pertama dalam pengujian adalah dengan mulai menjalankan coova chilli dengan perintah /etc/init.d/chilli start seperti pada Gambar 12 .

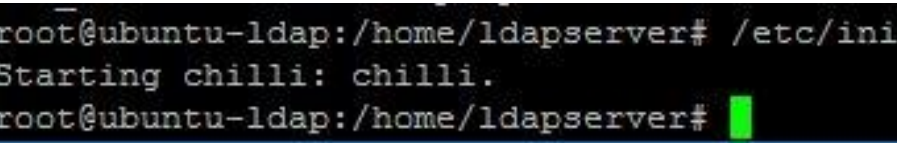

Gambar 12 Menjalankan program chilli

Captive portal mempunyai fungsi untuk memblok smua aliran paket data dan koneksi dari local ke publik dan mengharuskan client melakukan autentikasi terlebih dahulu apabaila terhubung ke jaringan publik atau internet. Untuk itu ketika kita menjalankan coovachilli untuk bisa memamkai fasilitas internet covachilli mempunyai fitur untuk membuat tunel secara otomatis dari Ethernet yang terhubung ke jaringan local dalam kasus ini Ethernet yang digunakan adalah eth1 dengan memberikan ip secara DHCP (Dynamic Host Control Protcol) dengan range ip 192.168.100.0/24 dan gateway 192.168.100.1 seperti pada Gambar 13

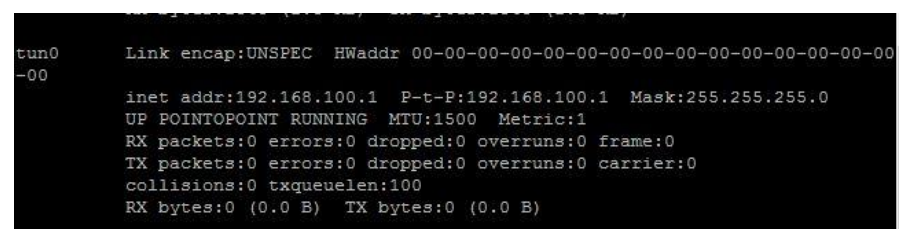

Gambar 13 Tunnel Gateway
Gambar 12 menunjukan seteah coovachilli aktif akan menjalankan tunneling secara otamtis sesuai dengan konfigurasi yang dibuat. Dalam kasus ini client dari jaringan lokal akan di beri rentang ip dari 192.168.100.2 sampai dengan 192.168.100.254 secara DHCP sehingga client tidak perlu mensetting ip secara manual baik secara wireless maupun kabel. Langkah selanjutnya mengkonfigurasi router wireless Linksys yang berfungsi membrodcast jaringan wifi pada jaringan lokal. Konfigurasi yang dilakukan adalah dengan cara membuant koneksi bridging pada lynksis sepert pada Gambar 14

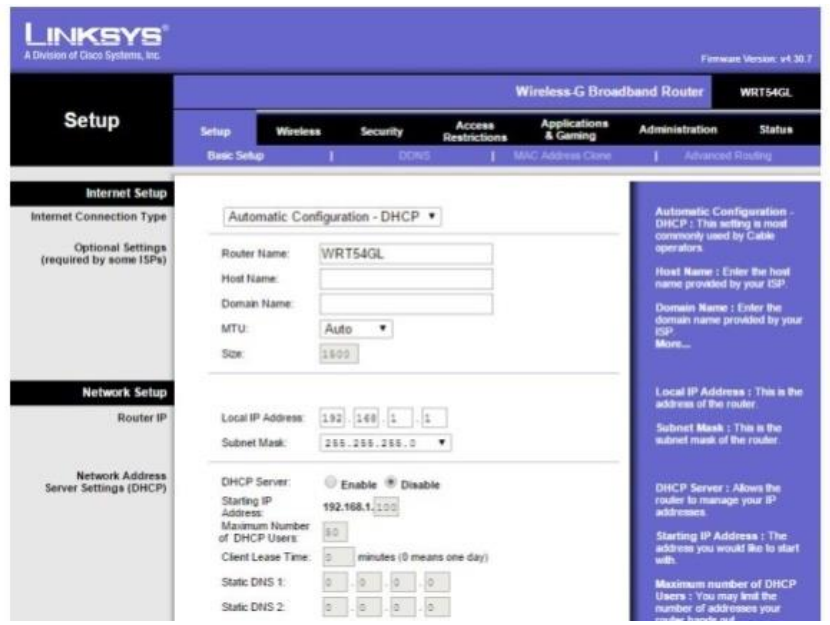

Gambar 14 Konfigurasi Bridge pada Router Linksys

Cara untuk membuat koneksi bridging adalah dengan membuat setiingan DHCP disable. Konfigurasi bridging berfungsi untuk bisa meneruskan koneksi dari captive portal agar konfigurasi captive portalakan diterima client secara langung. Saat ini captive portal sudah siap menerima request dari client, untuk mengujinya router Linksys harus terhubung dengan jaringan local dan mulai mengkasesnya melalu web browser seperti pada Gambar 15

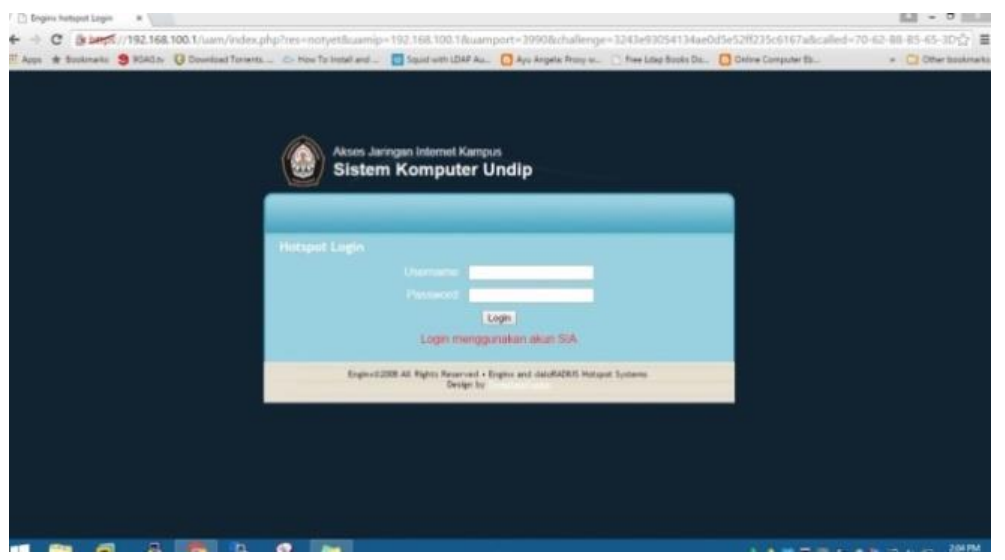

Gambar 16 Captive Portal Login

Setelah Captive portal berjalan, proses autentikasi akan di minta terus ketika client mengakses jaringan internet melalui web browser. Selama client belum melakukan porses autentikasi dihalaman login ini client tidak akan pernah bisa mengakses internet. Setiap kali client memasukan alamat url apapun halaman browser akan terus mendirect ke halaman login ini. Pengujian selanjutnya apakah client bisa melakukan autentikasi atau tidak, pada tahap ini akan mencoba dengan 
autentikasi dengan data akun Asep Unyil dengan username aunyil dan password asep1234 seperti pada Gambar 17

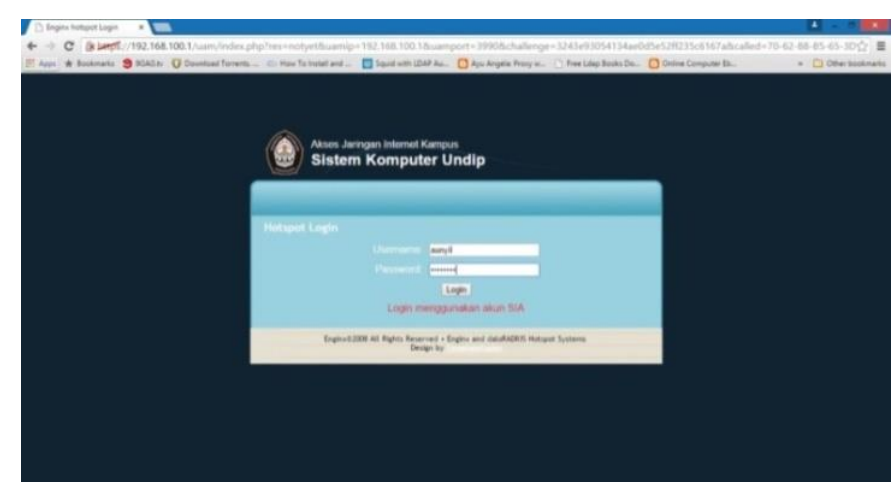

Gambar 17 Autentikasi User Aunyil

Jika proses autentikasi berhasil maka clientsudah bisa mengakses jaringan internet, kemudian pada web browser akan menambahkan sesi halaman web baru untuk halaman logout dan lamanya waktu ketika kita menggunakan internet. Seperti pada Gambar 18

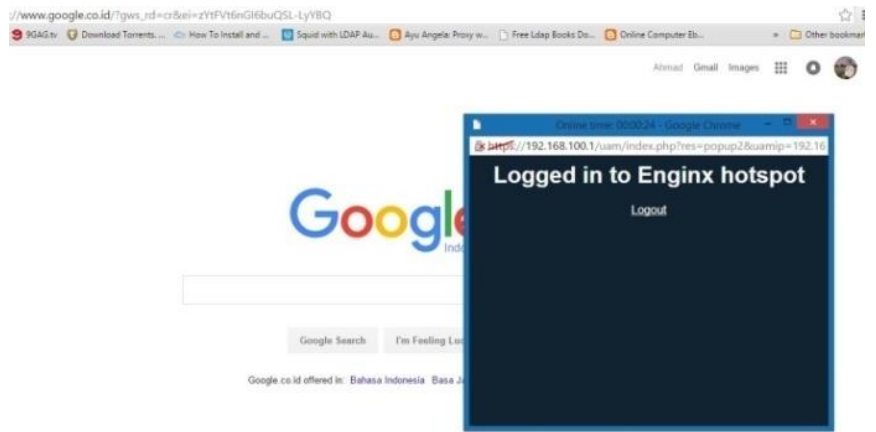

Gambar 18 Login berhasil

Tahap pengujian yang dilakukan menunjukkan sistem memiliki fungsi yang bekerja dengan benar.

\section{PENUTUP}

A

\section{Kesimpulan}

Selama pengembangan sistem ini terdapat beberapa hal yang bisa disimpulkan. Kesimpulan yang didapatkan antara lain:

1. Rancang bangun Sistem autentikasi hotspot menggunakan LDAP dan RADIUS telah berhasil dibangun pada jaringan internet kampus TEknik Sistem Komputer Univeristas Diponegoro. Sistem ini dibangun denga 2 mesin server dan 1 Router

2. Setiap server saling terintegrasi dan terkoneksi dengan jaringan internet kampus, Server RADIUS bisa melakukan ases ke database LDAP server menggunak Radtest.

3. Pembuatan user akun pada LDAP telah berhasil dengan menggunakan antarmuka phpldapadmin yang diakses melalu we browser

4. Proses autentikasi hotspot menggunakan antarmuka login captive portal covachilli yang memblok jaringan lokal sehingga client tidak diijinkan masuk pada jaringan internet kampus sebelum login.

5. Sistem keamanan pada LDAP server menggunakan SSL (Secure Socket Layer) dan autentikasi ganda ketika menggunakan antarmuka phpldapadmin.

6. Antarmuka Captive Portal akan terus melakukan redirect link ketika login gagal, sehingga client tidak bisa mengakses laman dan alamat web yang akan diakses.

7. Server RADIUS berhasil melakukan binding ke server LDAP pusat yang ada di Universitas Diponegoro untuk bisa melakukan proses autentikasi menggunakan akun SIA melewati perantara portal SSO (Single Sign On) Universitas Diponegoro.

\section{B. Saran}

1. Penelitian lanjutan untuk menenamkan sistem yang sudah ada dengan menambahkan kapasitas memori dan prosesor untuk diimplementasikan

2. Penelitian lanjutan untuk adanya pengelolaan akun SIA olen admistrator jaringan kampus.

3. Penelitian lanjutan untuk menambahkan kapasitas acces point agar lebih stabil ketika diakses oleh banyak mahasiswa. 


\section{DAFTAR PUSTAKA}

[1] Azikin, A. (2011). Debian GNU/Linux. Bandung: Informatika Bandung.

[2] Djunawidjaja, J. (2005). Integrasi User Account Dengan LDAP. Majalah Info Linux.

[3] Dwi Hantoro, G. (2005). Wifi (Wireless LAN). Bandung: Informatika Bandung.

[4] Komputer, Wahana. (2009). Langkah Mudah Administrasi Jaringan Menggunakan Linux Ubuntu. Yogyakarta: Andi Publisher Yogyakarta.

[5] Mulyono, H. 2. (2008). Buku Pintar Komputer. Jakarta: Kriya Pustaka Jakarta.

[6] S. Mulyanta, E. (2005). Pengenalan Protokol Jaringan. Yogyakarta: C.V Andi OFFEST Yogyakarta.
[7] Sugeng, W. (2010). Jaringan Komputer Dengan TCP/IP. Bandung: Modula Bandung.

[8] Sukmaji, A. R. (2008). Jaringan Komputer. Yogyakarta: Andi Publisher Yogyakarta.

[9] Syafrizal, M. (2008). Jaringan Komputer. Yogyakarta: Andi Publisher Yogyakarta.

[10] Wahyono, T. (2003). Prinsip Dasar Dan Teknologi Komunikasi Data. Yogyakarta: Amikom Yogyakarta.

[11] Survey. (2009, August 3). Retrieved July 14, 2015, from www.freeradius.org: http://freeradius.org/press/survey.html

[12] Openldap, Kurt D.Zeilenga. (2014, April 3). Retrieved October 9, 2015, from www.openldap.org: http://www.openldap.org/project/kurt/ 